\title{
Seasonal epidemiology of gastrointestinal nematodes of cattle in the northern continental climate zone of western Canada as revealed by internal transcribed spacer- 2 ribosomal DNA nemabiome barcoding
}

Tong Wang ${ }^{1 *}$, Elizabeth M. Redman ${ }^{1}$, Arianna Morosetti ${ }^{1}$, Rebecca Chen ${ }^{1}$, Sarah Kulle ${ }^{1}$, Natasha Morden ${ }^{1}$, Christopher McFarland ${ }^{2}$, Hannah Rose Vineer ${ }^{3}$, Douglas D. Colwell ${ }^{4}$, Eric R. Morgan ${ }^{2}$ and John S. Gilleard ${ }^{1 *}$

\begin{abstract}
Background: Gastrointestinal nematode (GIN) epidemiology is changing in many regions of the world due to factors such as global warming and emerging anthelmintic resistance. However, the dynamics of these changes in northern continental climate zones are poorly understood due to a lack of empirical data.

Methods: We studied the accumulation on pasture of free-living infective third-stage larvae (L3) of different GIN species from fecal pats deposited by naturally infected grazing cattle. The field study was conducted on three organic farms in Alberta, western Canada. Grass samples adjacent to 24 fecal pats were collected from each of three different pastures on each farm. Internal transcribed spacer-2 nemabiome metabarcoding was used to determine the GIN species composition of the harvested larvae. The rotational grazing patterns of the cattle ensured that each pasture was contaminated only once by fecal pat deposition. This design allowed us to monitor the accumulation of L3 of specific GIN species on pastures under natural climatic conditions without the confounding effects of pasture recontamination or anthelmintic treatments.

Results: In seven out of the nine pastures, grass $L 3$ counts peaked approximately 9 weeks after fecal deposition and then gradually declined. However, a relatively large number of $\mathrm{L} 3$ remained in the fecal pats at the end of the grazing season. Nemabiome metabarcoding revealed that Cooperia oncophora and Ostertagia ostertagi were the two most abundant species on all of the pastures and that the dynamics of larval accumulation on grass were similar for both species. Daily precipitation and temperature across the whole sampling period were similar for most of the pastures, and multiple linear regression showed that accumulated rainfall 1 week prior to sample collection had a significant impact on the pasture L3 population, but accumulated rainfall 3 weeks prior to sample collection did not.
\end{abstract}

Conclusions: The results suggest that the pasture L3 population was altered by short-term microclimatic conditions conducive for horizontal migration onto grass. Overall, the results show the importance of the fecal pat as a refuge

*Correspondence: tongwang0413@gmail.com; jsgillea@ucalgary.ca

${ }^{1}$ Host-Parasite Interactions Program, Faculty of Veterinary Medicine, University of Calgary, Calgary, Canada

Full list of author information is available at the end of the article

(c) The Author(s) 2021. Open Access This article is licensed under a Creative Commons Attribution 4.0 International License, which permits use, sharing, adaptation, distribution and reproduction in any medium or format, as long as you give appropriate credit to the original author(s) and the source, provide a link to the Creative Commons licence, and indicate if changes were made. The images or other third party material in this article are included in the article's Creative Commons licence, unless indicated otherwise in a credit line to the material. If material is not included in the article's Creative Commons licence and your intended use is not permitted by statutory regulation or exceeds the permitted use, you will need to obtain permission directly from the copyright holder. To view a copy of this licence, visit http://creativecommons.org/licenses/by/4.0/. The Creative Commons Public Domain Dedication waiver (http://creativeco mmons.org/publicdomain/zero/1.0/) applies to the data made available in this article, unless otherwise stated in a credit line to the data. 
and reservoir for $\mathrm{L} 3$ of cattle GIN on western Canadian pastures, and provide an evidence base for the risk assessment of rotational grazing management in the region.

Keywords: Gastrointestinal nematodes, Epidemiology, Grazing season, Internal transcribed spacer-2 ribosomal DNA metabarcoding, Microclimate

\section{Graphical Abstract}
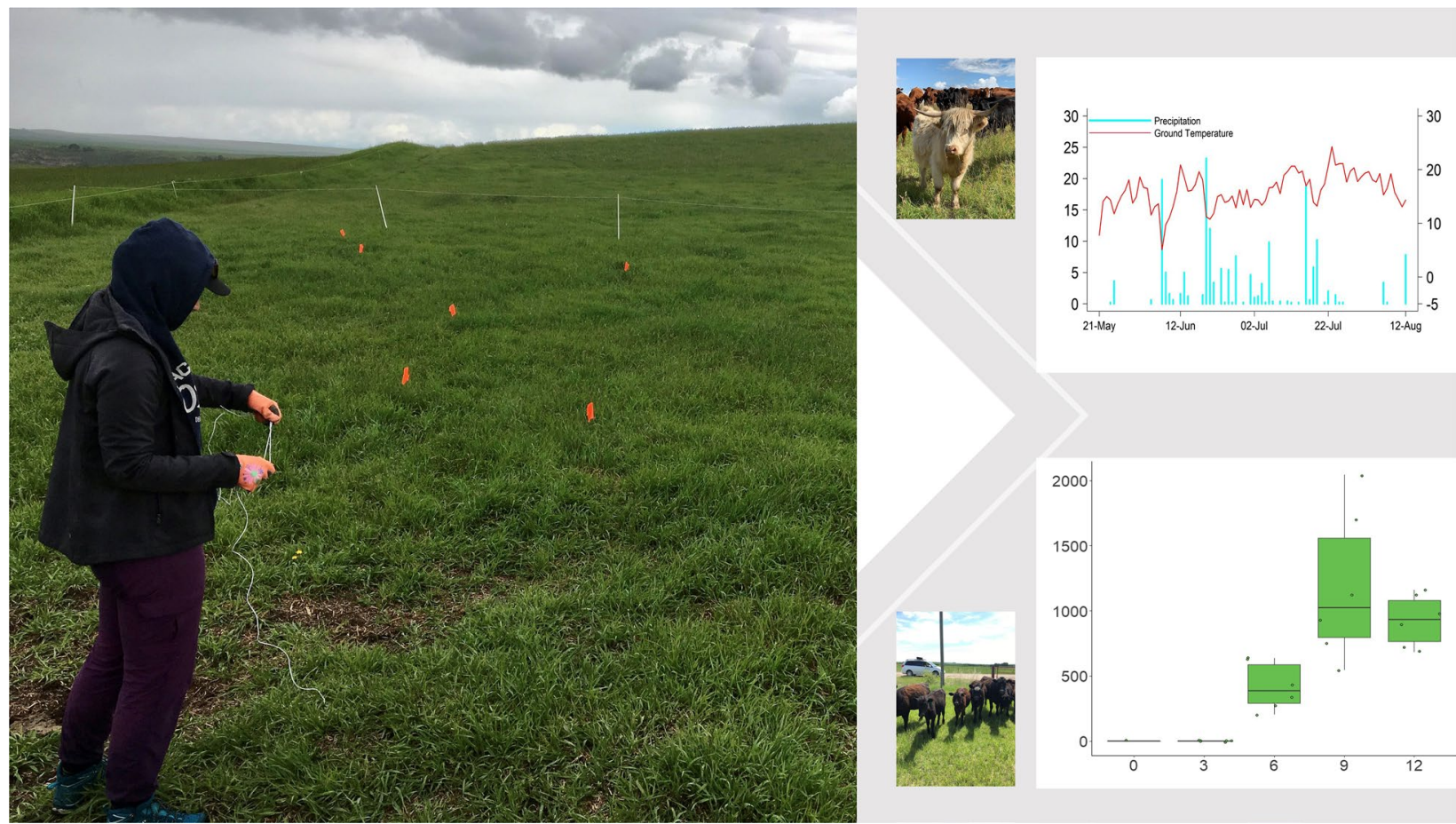

\section{Background}

Gastrointestinal nematodes (GIN) are amongst the most important pathogens of grazing ruminants worldwide, and have major negative impacts on animal health and production. In northern temperate regions, although clinical disease can occur in beef cattle that graze $[1,2]$, sub-clinical infection has a much greater impact and may go undetected by producers [3]. In temperate climate zones, the prevalence of cattle GIN is high, but the intensity of infection is generally lower than in sub-tropical and tropical regions [4]. However, GIN infection intensities appear to be increasing in temperate climate zones for a number of reasons, including climate change [5, $6]$ and the emergence of anthelmintic resistance [7, 8]. More northerly regions are particularly sensitive to these changes, and the epidemiology of cattle GINs in northern continental climate zones represents an important knowledge gap of relevance to the risk assessment and the implementation of evidence-based effective and sustainable GIN control practices.

A significant amount of work has been undertaken on the epidemiology of cattle GINs in temperate latitudes of the USA and Europe [9-12]. In temperate regions of the northern hemisphere, the infection of set-stocked cattle with overwintered GIN larvae begins after spring turnout onto pasture, while inhibited larvae in older hosts also mature at this time $[9,13]$. Eggs are produced during these early season infections which contaminate pasture and develop into infective third-stage larvae (L3), leading to a peak in adult worm abundance in mid-summer, prior to immunity-driven decline, while a proportion of the L3 linger on pasture and re-start the cycle the following year $[14,15]$. However, much less is known about the epidemiology of cattle GINs in more northerly continental climates. These locations differ from more temperate regions in several important ways, including the occurrence of extremely cold and dry winters and drier summers with sporadic but sometimes heavy precipitation [16]. Recent work has shown that L3 of both Ostertagia ostertagi and Cooperia oncophora can survive over the winter in significant numbers on pastures in western Canada, despite the very low temperatures and low humidity at this time of the year, with the fecal pat being an important refuge [13]. Fecal egg counts are known to 
increase over the summer grazing season in beef cattle in western Canada, and there is some evidence that temperature and accumulated precipitation are significant predictors of $O$. ostertagi serum antibody concentrations $[17,18]$. However, there is very limited information on the pasture dynamics of infective larvae over the grazing season in these northerly regions, and on whether there are differences between the major GIN species. These are important knowledge gaps since many of these regions, e.g. western Canada and northern USA, are major cattle grazing areas. Alberta alone possesses $41.6 \%$ of the Canadian beef cattle herd [19].

Co-infections of multiple GIN species are common in cattle worldwide, with species composition varying between regions $[20,21]$. Cooperia oncophora and $O$. ostertagi are the two most prevalent GIN species in western Canada $[8,13]$. Ostertagia ostertagi is the most pathogenic species in cattle, and although it can show anthelmintic resistance, reports of this are not common for North American beef cattle [22, 23]. In contrast, resistance to macrocyclic lactones has been documented in Cooperia species worldwide, including in North America [8]. Although Cooperia species are less pathogenic than O. ostertagi, they do cause production loss if poorly controlled [24], and are usually present in mixed infections with additive disease impacts [25,26]. Given the differences in the pathogenicity, epidemiology and drug sensitivity that exist among GIN species, species-specific information is important both for routine diagnostics and epidemiological studies. Nemabiome metabarcoding is a recently developed approach used to determine the relative proportions of strongylid species in fecal or pasture larval samples, and is well suited to epidemiological or surveillance studies involving large numbers of samples $[8,13,21]$.

In this paper, we present an investigation of the dynamics of pasture larval availability of the major GIN species in several beef cattle herds grazing over the summer in western Canada. The application of internal transcribed spacer (ITS)-2 nemabiome metabarcoding allowed the seasonal patterns of L3 of individual GIN species on pasture to be determined. The aim of this study was to determine the factors that influence the timing of L3 availability on herbage following the deposition of feces from grazing animals carrying natural mixed populations of GIN, and to provide support for evidence-based pasture management strategies.

\section{Methods \\ Study sites}

A field study was conducted on naturally infected pastures of three commercial organic beef cattle farms [located in Red Deer (farm 1), Waterton (farm 2) and Castor (farm 3), Alberta, Canada; $49^{\circ} 05^{\prime}-52^{\circ} 16^{\prime} \mathrm{N}$, $\left.111^{\circ} 54^{\prime} \mathrm{W}-113^{\circ} 91^{\prime} \mathrm{W}\right]$. None of the farms had used anthelmintics to treat GINs in the past 10 years. Each farm used an intensive rotational grazing pattern whereby the property was divided into small fields on which the herd sequentially grazed during the season (Table 1). Each herd was moved every 2 to 9 days to a new pasture that had not been grazed in the past 12 months, thus the cattle did not return to a pasture until the following grazing season. These features allowed us to monitor the seasonal ecology of free-living GINs under natural climatic conditions without the confounding effects of recontamination or anthelmintic treatment. We collected samples from three pastures on each farm, thus there were nine separate study pastures in total.

\section{Meteorological data}

One solar-powered weather station (HOBO RX3000; Onset, MA) was set up on each farm, with probes at $1 \mathrm{~cm}$ above ground level (which is where GIN larvae reside on herbage). Temperature and precipitation data were recorded every $15 \mathrm{~min}$ and transferred hourly to HOBOlink Web-based software (https://www.hobolink. $\mathrm{com} /$ ) with which the latest data could be downloaded. We chose to measure temperature closer to the ground than is typical for weather stations as this better represents the microclimate experienced by GINs in fecal pats and on pasture [27].

\section{Experimental design and environmental sampling}

The field study was conducted from June to October 2019 and the study sites were visited at 3-week intervals for sample collection, starting from the third week after fecal deposition. Figure 1 illustrates the detailed experimental design that was used for all three farms. The total

Table 1 Pasture and grazing information for the three study farms in Alberta, western Canada

\begin{tabular}{llll}
\hline Farm & Farm 1 & Farm 2 & Farm 3 \\
\hline Herd size & 110 Yearlings & 80 Yearlings & 25 Yearlings and 110 cows \\
Pasture size (each field) & $25-40$ Acres & 160 Acres & 10 Acres \\
Rotation frequency & Every 2 days & Every 5 days & Every 7-9 days \\
Breed of cattle & Crossbred beef cattle & Crossbred beef cattle & Crossbred beef cattle \\
\hline
\end{tabular}




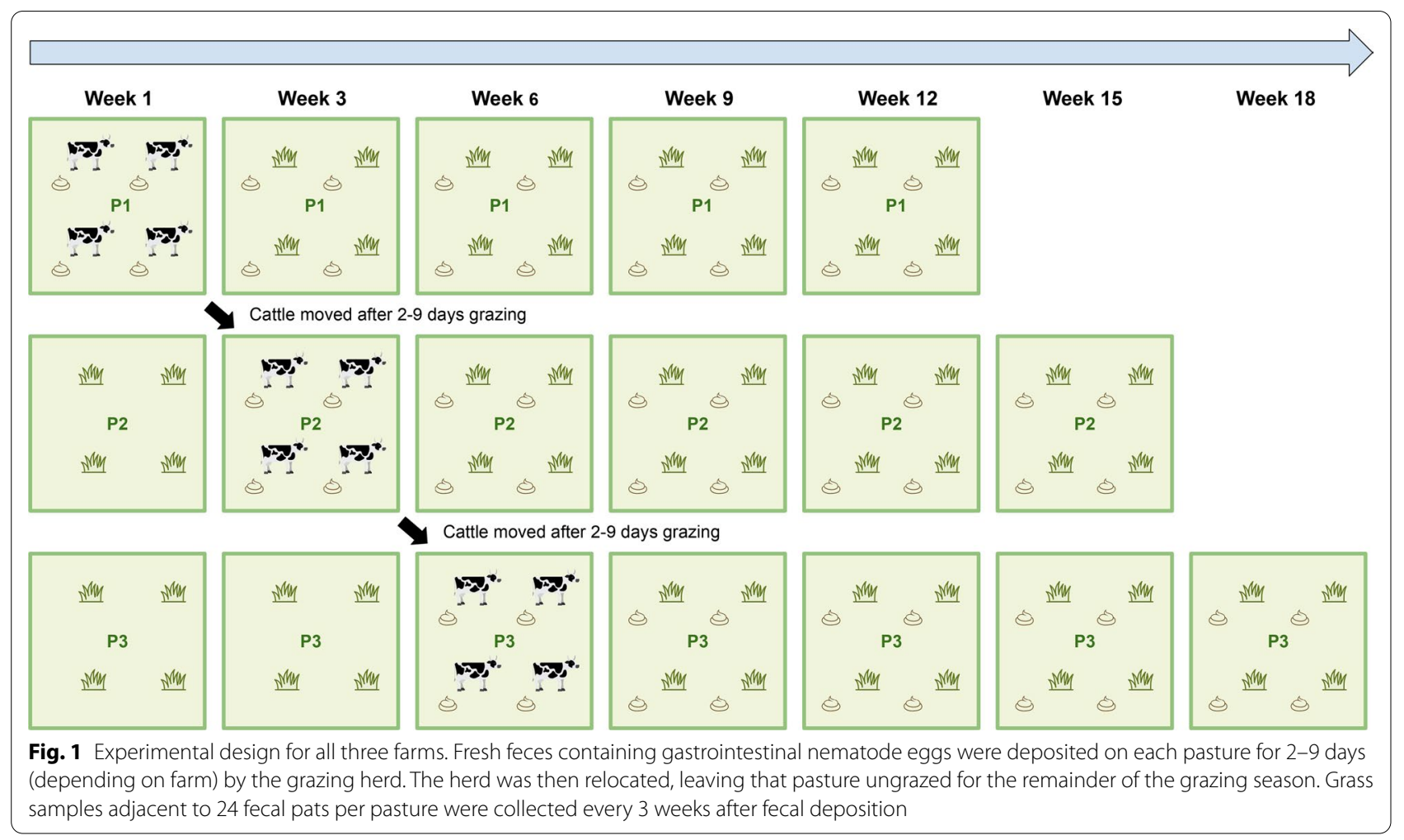

sampling period was from 3 weeks until 12 weeks after fecal deposition (except for pastures 1 and 2 on farm 3). The sampling dates for each pasture are shown in Additional file 1: Table S1. The experimental design allowed us to study the population dynamics of free-living GINs on each pasture for the remainder of the grazing season without any further contamination from grazing cattle.

On each pasture, grass sampling was performed around 24 random fecal pats in decent condition. Each fecal pat was labelled with an identification flag to allow the collection of grass from one of four $30 \times 30-\mathrm{cm}\left(900-\mathrm{cm}^{2}\right)$ quadrants immediately adjacent to the pat every 3 weeks throughout the grazing season. During each sampling visit, grass on one of the four quadrants adjacent to each pat was cut to ground level with a pair of grass shears (Fiskars, Finland) (Fig. 2a), on the basis that the vast majority of L3 migrate no further than $30 \mathrm{~cm}$ from deposited feces [28]. Sampling was conducted clockwise around each fecal pat. In order to keep the laboratory work to a manageable scale, on each sampling occasion, grass samples from four pats were pooled to give a total of six sampling units per pasture. Material from around the same four pats was pooled on each sampling occasion. A total of 864 grass samples (equivalent to 216 sampling units) were collected during the study period. We estimated the total number of L3 migrating from the fecal pats onto the corresponding area of grass using this quadrant sampling technique. The study area was protected by fencing to prevent disruption by wildlife (Fig. 2b). All of the grass samples were stored in sealed plastic bags during transport and analyzed within $24 \mathrm{~h}$. At the end of the study, the 24 labelled pats were collected from five of the nine pastures (two pastures on farm 2 and all three pastures on farm 3), to examine how many L3 remained in the pats. Pats were not collected from all nine pastures because of labour and scheduling issues.

\section{Recovery of $L 3$ from grass and fecal samples}

Grass and fecal L3 recovery methods were validated by spiking $100 \mathrm{~g}$ of parasite-free grass with around $1000 \mathrm{~L} 3$ (Additional file 2: Text S1). The recovery rates of the grass and fecal L3 protocols were $22.0 \%$ and $14.4 \%$, respectively, and were applied to the calculation of available L3. Grass samples were processed following a flotation and sieving protocol, as described by Wang et al. [13]. The total number of L3 that migrated from one fecal pat onto grass $(L 3 \mathrm{~g})$ was calculated as follows:

$$
\mathrm{L} 3 \mathrm{~g}=\frac{\mathrm{L} 3 \mathrm{~s} \times 4}{4 \times 0.22}
$$

where $L 3 \mathrm{~s}$ is the number of L3 in each sampling unit. L3s is multiplied by 4 as a result of the quadrant-type sampling technique, where only $25 \%$ of the total grass around each fecal pat was collected on a sampling occasion; the 


\section{a}

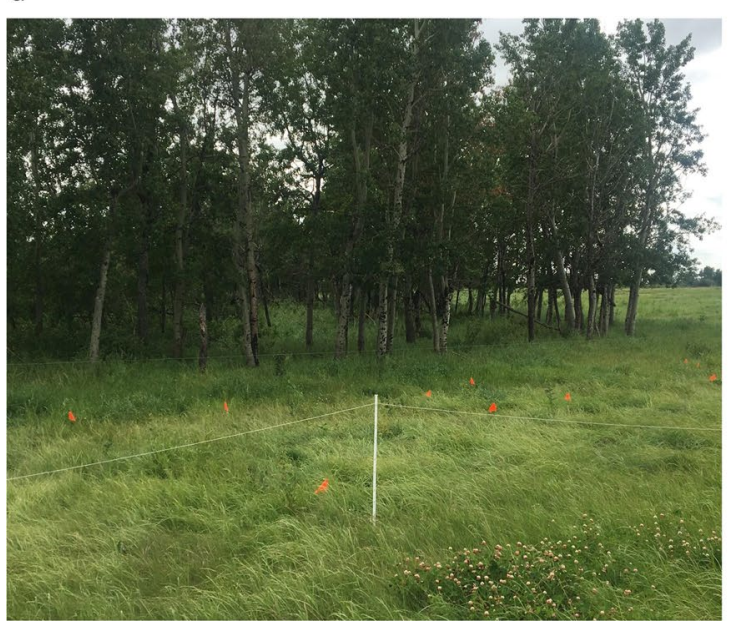

b

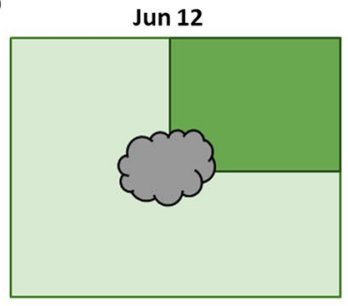

Aug 12

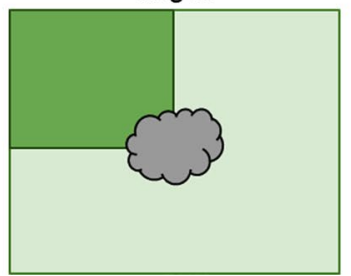

Jul 2

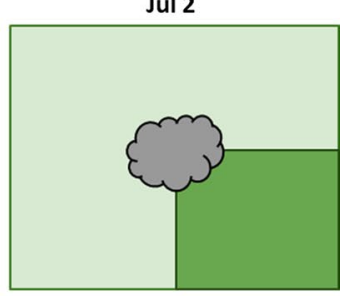

Jul 22

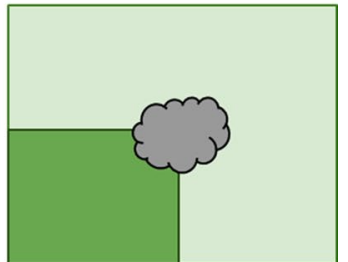

Fig. 2 a On each pasture, 24 fecal pats were labelled with identification flags so that grass samples could be collected every 3 weeks from around the same pat. Fencing was set up to protect the sampling area from wildlife. $\mathbf{b}$ Schematic of the sampling method. Each sampling visit, grass samples were collected from one of the four $30 \times 30-\mathrm{cm}$ quadrants surrounding a pat. The quadrants were cut in clockwise order over the study period

product is then divided by the grass L3 recovery rate (0.22) multiplied by 4 , as each sampling unit contained L3 from four fecal pats.

At the end of the study, each pat collected from the five pastures was processed individually and thoroughly mixed with a kitchen blender (72-oz 1500-W Ninja Pulse Control Blender; USA). A 30-g aliquot was processed to harvest L3 using a modified Baermann technique [29]. The total number of L3 in each fecal pat (L3f) was calculated as follows:

$$
\mathrm{L} 3 \mathrm{f}=\frac{\mathrm{L} 3 \mathrm{a} \times \mathrm{Wt}}{\mathrm{Wa} \times 0.144}
$$

where $L 3$ a is the number of L3 per aliquot, Wa is weight of the aliquot, Wt is the weight of the whole fecal pat from which the aliquot was derived; 0.144 is the fecal L3 recovery rate.

Trichostrongylid L3 were distinguished from free-living nematodes based on key morphological features such as the presence of a sheath tail extension and filament [30]. The number of $\mathrm{L} 3$ in a 1-ml aliquot was determined using a counting chamber (Sedgewick Rafter, UK) under $\times 4$ magnification, and the whole sample population on each collection date was fixed in $70 \%$ ethanol for molecular analysis.

\section{ITS-2 ribosomal DNA nemabiome metabarcoding}

Nemabiome metabarcoding was performed as previously described [21]. In brief, a commercial kit (DNeasy PowerSoil; Qiagen, Hilden, Germany) was used to extract DNA from L3 recovered from environmental samples of feces and grass after they had been pooled by pasture and date. The ITS-2 ribosomal DNA (rDNA) target was amplified by polymerase chain reaction (PCR), and libraries prepared and deep sequenced as previously described [13]. In brief, a 350-bp fragment encompassing the rDNA ITS-2 was amplified by PCR from a 1:10 dilution of genomic DNA template. A second round limited-cycle PCR was performed to add combinatorial barcoding adapters to allow amplicons from many populations to be pooled and then sequenced on an Illumina MiSeq Sequencer using a 500-cycle pair-end reagent kit (MiSeq Reagent Kits v2, MS-103-2003; Illumina, San Diego, CA), and a mean read depth of 20,458 (range 9,068-31,196) was generated. Further details of the protocols are available at www.nemabiome.ca.

\section{Bioinformatic analysis}

Short-read sequence data were analysed using a bioinformatic pipeline based on DADA2 [31]. Firstly, raw pairedend reads were pre-filtered and primers were removed using the cutadapt function. Then read filtering was used as a quality control process: non-structural reads were removed from the reads by the pipeline; the settings allowed two and five expected errors for forward and reverse reads, respectively. Forward and reverse reads were either merged or, if there was insufficient overlap, concatenated. An amplicon sequence variant (ASV) table was then created and chimeras removed. A recently developed database of nematode rDNA ITS-2 reference sequences was used [32]. Finally, IdTaxa was used as the classification algorithm to classify the ASVs from the 

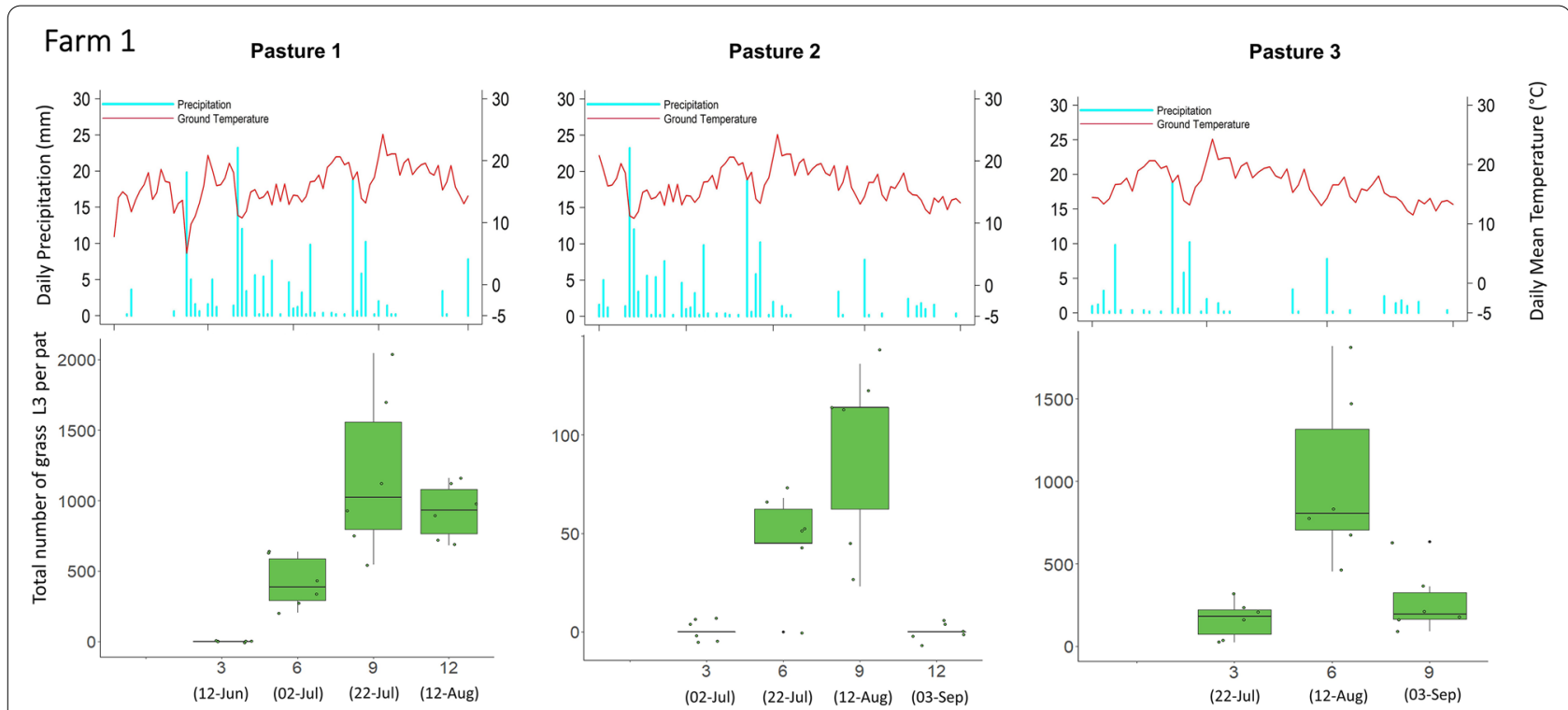

Fig. 3 Infective third-stage larval (L3) count from grass samples taken adjacent to fecal pats (lower panels) with corresponding daily precipitation and daily mean ground temperature (upper panels) for farm 1. At each sampling time, the six data points correspond to six sampling units (four fecal pats per sampling unit). The $x$-axis on the lower plots indicates the number of weeks after fecal pat deposition, with sampling dates in parentheses. Each pasture was grazed only once for a 2- to 9-day period. Pasture 3 was not sampled at week 12 because the flags that identified the pats had been removed by wildlife

pipeline at the highest resolution using the database. We used a classification confidence of $60 \%$ as the threshold when assigning the ASVs to species level, as suggested by Murali et al. [33]. Detailed information regarding this protocol can be found at https://www.nemabiome.ca/ dada2_workflow.html.

\section{Statistical analysis}

The daily mean precipitation and temperature were calculated from the meteorological data that were recorded every $15 \mathrm{~min}$, following the downloading of data from the on-farm weather stations. A non-parametric WilcoxonMann-Whitney test was applied to compare the daily precipitation and temperature for each of the nine sampling pastures over each specific sampling period.

The total number of L3 (which had migrated from the feces) on the grass around each pat was determined from the L3 count, as above. The total number of L3 was then converted to the number of L3 of each individual GIN species based on the relative quantitative data derived from the nemabiome analyses. To test the effect of environmental factors on the number of L3 of C. oncophora and $O$. ostertagi present on the grass surrounding the fecal pats, individual species' data for all nine pastures were combined in a single dataset. L3 abundance at each collection point was log transformed and the data for each individual species analyzed in a separate multiple linear regression with the significance of independent variables determined by ANOVA. We selected the best model from the set of candidate models using a stepwise Akaike information criterion approach [34]. It was assumed that 3 weeks was the maximum development time from egg to L3 stage under the conditions observed in the study, so the independent variables were Mean temperature 3 weeks before sample collection, Total precipitation 3 weeks before sample collection, Total precipitation 1 week before sample collection, Days after egg deposition, and Pasture. Tukey's post hoc test was applied to significant outcomes of the categorical variable (Pasture). The statistical analyses were carried out in RStudio [RStudio Team, 2016, Integrated Development for R; RStudio, Boston, MA (http://www.rstudio.com/)].

\section{Results}

\section{Grass L3 count and corresponding meteorological data}

Overall, and with few exceptions, the mean grass L3 count per fecal pat across all nine pastures was lowest at week 3 (mean = $36 \mathrm{~L} 3 /$ pat), followed by an increase at week $6($ mean $=311 \mathrm{~L} 3 /$ pat$)$, then the peak at week 9 (mean 562 L3/pat), followed by a decrease at week 12 (mean $=314 \mathrm{~L} 3 /$ pat). Results for each pasture with corresponding meteorological data recorded during the study period are shown in Figs. 3, 4 and 5. 

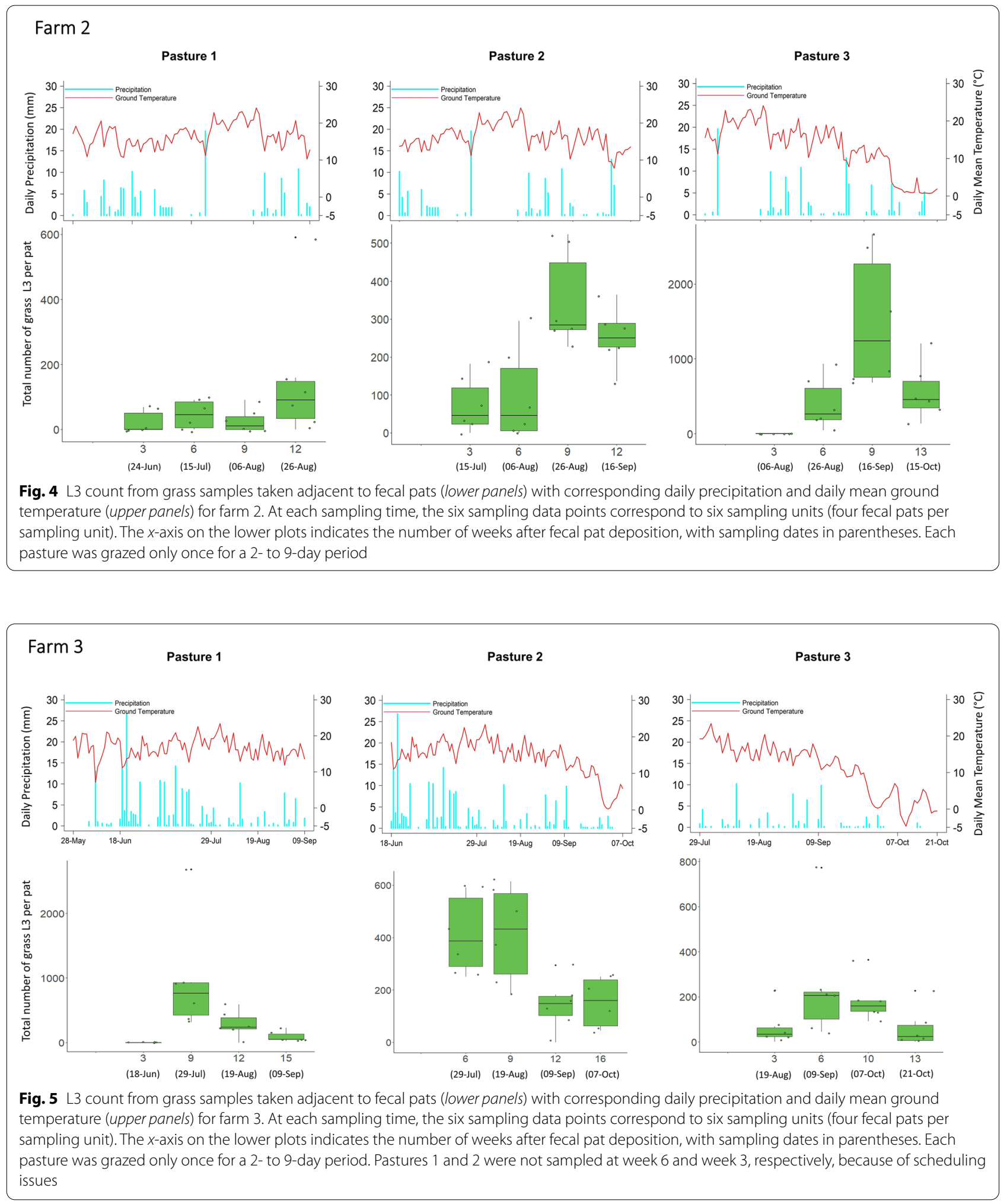

Comparison of daily meteorological data between pastures There was no statistically significant difference in overall daily precipitation between any of the pastures. The ground temperatures of pasture 3 on farm 2 and of pasture 3 on farm 3 were statistically significantly lower than those of the other pastures (Fig. 6). 


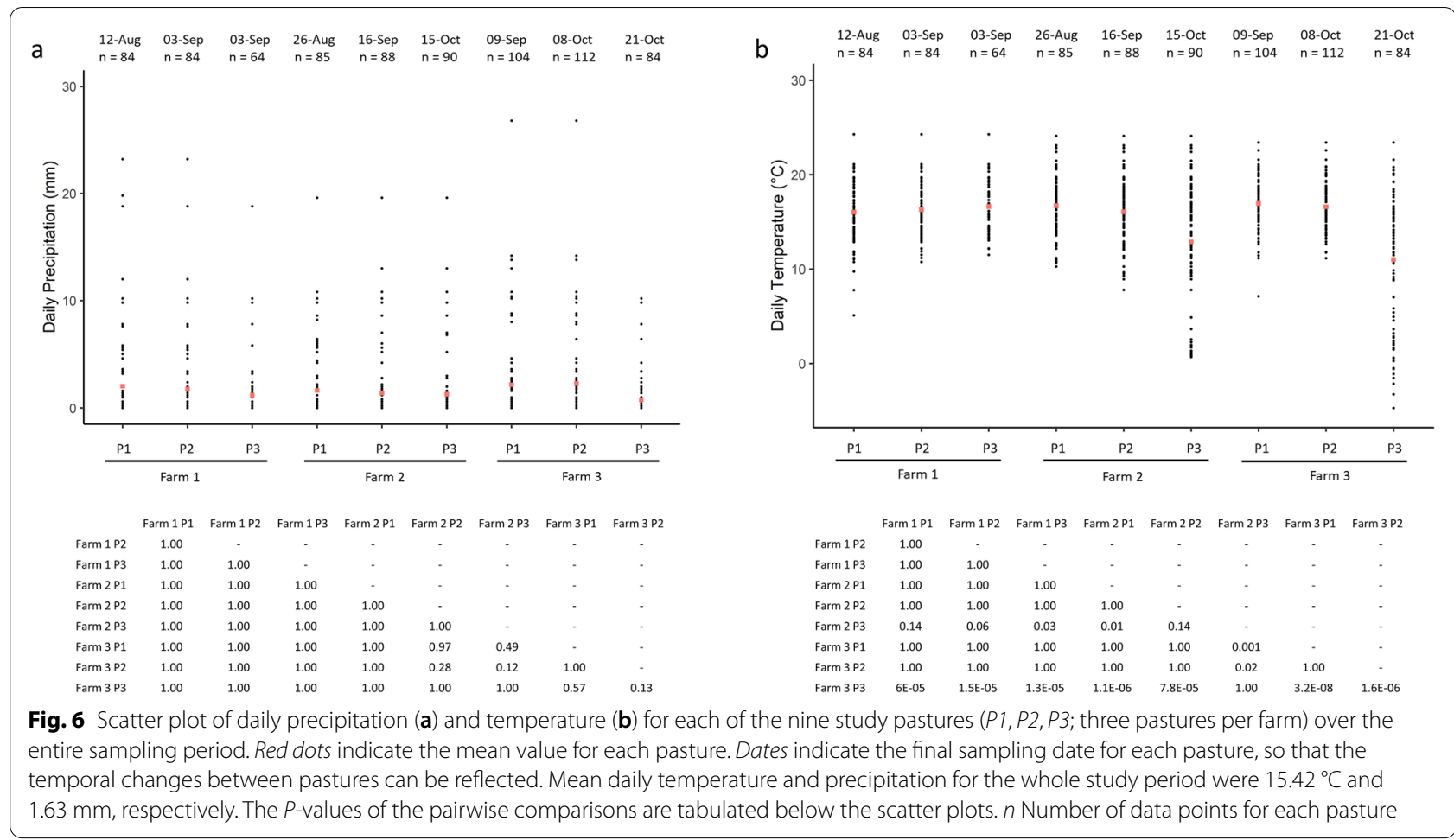

Table 2 Mean $( \pm S D)$ fecal infective third-stage larval (L3) count for five pastures on the last sampling date

\begin{tabular}{lll}
\hline & Fecal L3 count $^{\text {a }}$ & Grass L3 count \\
\hline Farm 2, pasture 2 & $1846(3649)$ & $254(70)$ \\
Farm 2, pasture 3 & $20,274(20,544)$ & $557(347)$ \\
Farm 3, pasture 1 & $361(824)$ & $91(75)$ \\
Farm 3, pasture 2 & $1859(4642)$ & $144(90)$ \\
Farm 3, pasture 3 & $2738(3878)$ & $182(87)$
\end{tabular}

Sample size for fecal and grass groups is 24 and 6, respectively

${ }^{a}$ Fecal L3 count is expressed as the total number of L3 per fecal pat at the time of collection

${ }^{b}$ Grass L3 count is the estimated total number of L3 on the grass surrounding each pat on the last sampling date

\section{Fecal L3 count at the end of the study}

The mean number of L3 remaining in each fecal pat, and the proportion of total L3 migrating out of the fecal pat for that pasture, are shown in Table 2. For all five pastures from which fecal pats were sampled, the overall mean number of larvae that remained in the pats and recovered from the adjacent grass at the last sampling point were $5416(\mathrm{SD} \pm 7468)$ and 246 $(\mathrm{SD} \pm 165)$, respectively .
GIN species-specific pasture L3 counts over the grazing season interpolated from ITS-2 rDNA metabarcoding data The pasture L3 population of each GIN species was estimated from the total L3 values by interpolation using the GIN species proportions determined by ITS-2 rDNA nemabiome sequencing (Fig. 7). The most prevalent species on all farms throughout the grazing season was $O$. ostertagi, followed by C. oncophora. Nematodirus helvetianus and Trichostrongylus axei were also detected, but only at low proportions (means of $4.2 \%$ and $1.6 \%$, respectively). Similar proportions of O. ostertagi and C. oncophora L3 were isolated for all three farms and throughout the grazing season. The overall grass count of $O$. ostertagi, C. oncophora, $N$. helvetianus and T. axei per fecal pat was $165,169,9$ and 8 , respectively.

\section{Relationships between climate variables and pasture L3 levels}

Multiple linear regression was applied to C. oncophora and $O$. ostertagi datasets to test the association of five predictor variables with pasture L3 count of each species. In the case of $C$. oncophora, the predictor variables explained a significant amount of variance in the L3 count $\left[F_{(13,148)}=19.14, P<0.0001, R^{2}=0.63\right]$ showing that Total precipitation 1 week before sampling and Days after egg deposition contributed significantly to pasture larval count. However, Mean temperature 3 weeks 

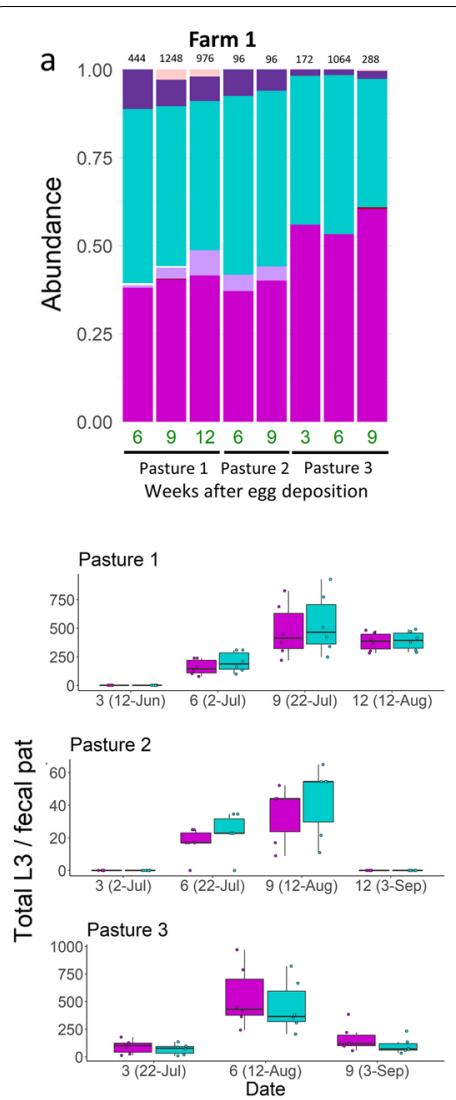
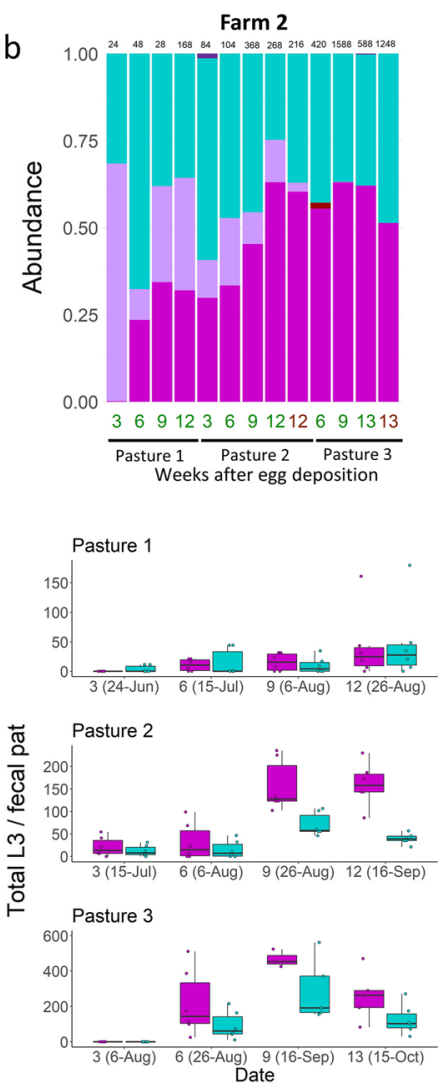
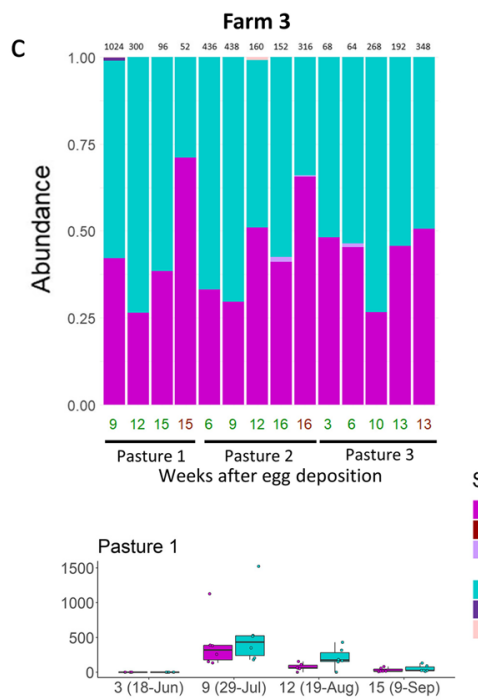

Species

Cooperia oncophora Haemonchus placei Oesophagostomum radiatum Ostertagia ostertagi Trichostrongylus axei unclassified Trichostrongylus

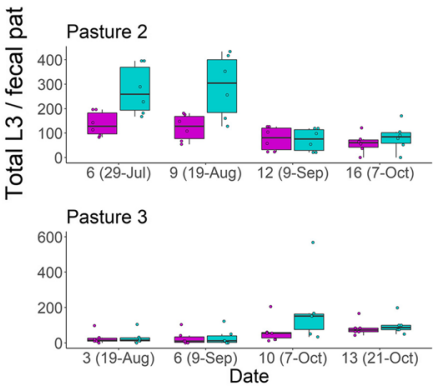

Fig. 7 Relative species abundance in samples taken from farm 1 (a), farm 2 (b) and farm 3 (c) as determined by internal transcribed spacer-2 ribosomal DNA nemabiome metabarcoding of $\mathrm{L} 3$ populations pooled by sampling date and pasture. On the $x$-axis, sample numbers in green indicate grass samples, while those in brown indicate fecal samples. The number of L3 in each pool from which genomic DNA was isolated is shown above each bar. The bar charts show pasture $\mathrm{L} 3$ count for each species as determined by incorporating metabarcoding results with overall pasture L3 count

before sampling and Total precipitation 3 weeks before sampling were not statistically significant predictors (Table 3). Tukey's post hoc honest significant difference (HSD) test was used to compare C. oncophora L3 harvest between pastures of the same farm. On farm 1, significantly fewer L3 were recovered from pasture 2 than from pastures 1 and $3(P<0.001)$. On farm 2 , significantly more L3 were recovered from pasture 3 than from pastures 1

Table 3 Results of multiple linear regression on the number of $L 3$ recovered from the grass surrounding fecal pats in relation to climate variables for the two main nematode species found in the study, Cooperia oncophora and Ostertagia ostertagi

\begin{tabular}{|c|c|c|c|c|}
\hline & \multicolumn{2}{|l|}{ C. oncophora } & \multicolumn{2}{|l|}{ O. ostertagi } \\
\hline & Regression coefficient & $P$-value & Regression coefficient & $P$-value \\
\hline Mean temperature 3 weeks before sampling & -0.0215 & 0.540 & -0.0317 & $0.019^{*}$ \\
\hline Total precipitation 3 weeks before sampling & -0.0117 & 0.897 & -0.0116 & 0.105 \\
\hline Total precipitation 1 week before sampling & 0.02326 & $0.008^{* * *}$ & 0.01631 & $0.005^{* *}$ \\
\hline Days after egg deposition ${ }^{2}$ & -0.00039 & $0.006^{* * *}$ & -0.00044 & $<0.001^{* * *}$ \\
\hline Intercept & 5.215 & & 5.790 & \\
\hline$R^{2}\left(R^{2}\right.$ adjusted $)$ & $0.63(0.6)$ & & $0.51(0.46)$ & \\
\hline
\end{tabular}

Mean temperature in the 3 weeks prior to sampling was also included, but its effect was not significant

${ }^{*} P<0.05,{ }^{* *} P<0.01,{ }^{* * *} P<0.001$ 
and $2(P<0.001)$. There was no significant difference in the L3 harvest between pastures on farm 3 . The predictor variables also explained a significant amount of variance in the $O$. ostertagi $\mathrm{L} 3$ count $\left[F_{(13,148)}=11.7, P<0.0001\right.$, $\left.R^{2}=0.51\right]$. While Mean temperature 3 weeks before sampling, Total precipitation 1 week before sampling and Days after egg deposition contributed significantly to the model, Total precipitation 3 weeks before sampling did not (Table 3). In contrast with C. oncophora, Mean temperature 3 weeks before sampling was significantly associated with $O$. ostertagi L3 harvest. Tukey's post hoc HSD test was used to compare O. ostertagi L3 harvest between the pastures of the same farm. On farm 1, significantly fewer L3 were recovered from pasture 2 than from pastures 1 and $3(P<0.001)$. On farm 2 , significantly more L3 were recovered from pasture 3 than from pasture $1(P<0.001)$. On farm 3 , significantly more L3 were recovered from pasture 2 than from pasture $3(P=0.014)$.

\section{Discussion}

A detailed understanding of the population dynamics of GINs throughout the grazing season is crucial to support evidence-based control strategies. In this study, we investigated the pasture larval ecology of cattle GINs in the northern continental climate zone of western Canada. The number of L3 that appear on grass is the net effect of multiple aspects of the free-living phase of the parasite's life cycle, from development inside the egg to hatching, development from L1 to L3, and migration onto pasture [28]. Our experimental design allowed us to monitor the free-living infective L3 accumulating on the grass surrounding the fecal pats over time during the summer grazing season. Since macroparasites such as GINs commonly have an aggregated distribution among a host population [35], and spatial distribution on pastures [36], substantial variability can be detected in field studies. To mitigate this, our study design was focused on the grass surrounding identified fecal pats rather than across the pastures in general, with repeated sampling of the grass surrounding a total of 24 fecal pats per pasture, for three separate pastures on each of the three farms.

One striking result was that the grass L3 count peaked very consistently at around 9 weeks after fecal pat deposition on seven of the nine pastures sampled; small numbers of L3 appeared at 3 weeks after egg deposition on these pastures, and there was a decline in the number of L3 after 9 weeks. The remarkably similar timing of the peak of infective larvae between pastures is of particular note since both moisture and temperature have been shown to play an important role in larval development and the migration of L3 from dung onto herbage [37]. Temperature and precipitation were very similar between the pastures, and this may account for the similarity in the timing of their pasture larval peaks. Two pastures which were monitored later on in the grazing season and into October, experienced lower overall ground temperatures during the sampling period, thus, the average ground temperatures were lower after the period of larval development in the pats on these pastures.

Larval counts on grass may have declined after 9 weeks due to a combination of reduced larval activity, a reduced density of larvae remaining in the fecal pat, and the overall lower level of precipitation later on in the grazing season (Fig. 6). The L3 that had already translocated onto pasture could have either suffered high mortality from desiccation [38] or migrated downwards into the soil [39]. Multiple linear regression showed that accumulated rainfall 1 week prior to sample collection had a significant impact on the pasture L3 population, but accumulated rainfall 3 weeks prior to sample collection did not, suggesting that the pasture L3 populations depend significantly on short-term microclimatic conditions for horizontal migration onto pasture rather than longer term microclimatic variation. For GINs of sheep, rainfall is crucial for their migration out of feces [27]; earlier in the cycle, moisture within the feces is adequate for development except under the driest conditions [40], while free water is not needed for vertical migration onto grass [41, 42]. This situation is likely to be even more marked for GIN in cattle, whose larger fecal pats retain moisture for longer periods but form a thicker surface crust of dried feces, which hinders larval migration. More research is required on the climatic constraints of larval migration from cattle dung to herbage. Empirically, however, it is clear that periods of dry weather can delay larval availability in temperate (e.g. [43]) and semi-arid regions (e.g. [44]), while the sequestration of larvae in dung in the absence of rainfall could explain the lack of a 9-week peak in L3 abundance on pasture 1 of farm 2. Temperature over the previous three weeks was associated with L3 availability for O. ostertagi but not for C. oncophora, and might indicate a greater temperature sensitivity of developing larvae within the pat for the former species.

Our results suggest that peak larval abundance occurs approximately nine weeks after fecal pat deposition in the northern continental summer, and provide supporting empirical data for basic risk assessments and grazing management advice. For example, in the rotational grazing systems of western Canada, moving cattle to new pastures within three weeks is likely to largely eliminate the risk of reinfection with GINs, while slightly longer periods would allow moderate re-infection (e.g. to preserve refugia post-treatment), while still preventing a peak of L3 density occurring at 6-nine weeks. Return intervals can also be determined by taking into consideration declining L3 abundance; although we did not track the 
fate of the L3 remaining in the dung pats after 12 weeks, this may have indicated that it was better to prolong the period of time until re-grazing was considered safe. Clearly, in cases where there are large temperature and precipitation differences to those observed here, such assumptions would not be valid, although a similar grazing interval to the one used here seems to control GIN effectively in temperate zones [45]. Predictive modelling studies are a potentially powerful way to build on this baseline information to provide guidance across a wider range of climatic conditions [46].

The results of studies on parasite epidemiology that examine natural infections are difficult to interpret because of the difficulty of identifying the species composition of mixed field populations. Species-specific studies generally involve either placing fecal samples infected with a laboratory cultivated species into the field (e.g. [47]) or allowing artificially infected animals to graze and contaminate monitored pastures (e.g. [9]). Nogareda et al. [11] identified the species composition of adult worms at necropsy of tracer calves; however, carrying out this type of study might be problematic in some countries due to prevailing animal ethics, as well as associated costs and logistical challenges. In contrast, ITS-2 rDNA nemabiome metabarcoding can accurately quantify GIN species composition in a mixed field population, which makes the direct analysis of pasture contamination derived from naturally acquired infections more feasible. $O$. ostertagi and $C$. oncophora were the most abundant species in the present study; they were present on all of the pastures, although small numbers of $N$. helvetianus and T. axei were also detected on some pastures. The larval dynamics were essentially the same for O. ostertagi and $C$. oncophora, which suggests that a standard grazing management plan would be equally effective for both, at least from the perspective of larval ecology. Differences in the acquisition of immunity for these two species, however, may have an impact on production following re-exposure [48]

Another interesting finding of this study was the relatively large number of infective L3 recovered from fecal pats at the end of the grazing season. This result suggests that the fecal pat is an important refuge for L3 and could act as a reservoir for pasture contamination for an extended period of time. The estimated mean proportion of the L3 population that migrated out of fecal pats onto grass during the course of the grazing season was between $10.3 \%$ and $78.7 \%$, depending on the pasture (Additional file 3: Table S2). This suggests that short intense periods of rainfall could still allow substantial numbers of L3 to leave dung pats even later in the grazing season. It also highlights the importance of further investigation into the impact of short-term weather variability on pasture infectivity and the potential role of predictive modelling in risk assessment and grazing management. Our findings on the importance of the fecal pat as a refuge and reservoir of infective L3 during the grazing season builds on our previous work which showed the importance of the fecal pat as a refuge enabling O. ostertagi and C. oncophora L3 survival on pastures over the winter in western Canada [13]. Under temperate northern European climate conditions, the mortality rates of $O$. ostertagi and C. oncophora L3 were substantially higher in feces than on herbage, and migration from feces was found to be little influenced by microclimate [49]. In northern continental climate zones, however, dry periods might inhibit larvae from migrating from feces, and cold weather might reduce their survival on herbage, hence increasing the relative importance of dung pats as a larval reservoir. Delayed migration of L3 from pats could alleviate infection pressure in the summer, but might also slow down the build-up of immunity [50] and increase autumn exposure and hence hypobiosis and the subsequent risk of type II ostertagiosis [45, 51]. Altered mixing of resistant and susceptible genotypes following anthelmintic treatment, due to larval sequestration and release, could also impact the effectiveness of refugia-based parasite control strategies $[52,53]$. The implications of fecal larval sequestration for parasite control practices in cattle in northern continental zones could be far-reaching, and require further research in order to support advice given to producers. Changing climates in other parts of the world, for example drier summers in temperate zones [46], might also increase the epidemiological significance of this phenomenon for parasite control in the future.

\section{Conclusions}

This detailed investigation of pasture L3 dynamics during the grazing season in western Canada considerably improved our understanding of the epidemiology of GINs in this region. On most pastures, L3 could not be recovered in large numbers until 6 weeks after fecal deposition, and the L3 count peaked at the 9th week after fecal deposition. A large number of larvae remained in the fecal pats at the end of grazing season, which suggests that fecal pats are important refuge for larvae under the climatic conditions reported here. Short-term rainfall seems to have an important effect on the migration of larvae from the fecal pat onto pasture. Cooperia oncophora and O. ostertagi were the two most predominant species, with comparable seasonal prevalence and abundance across the multiple locations examined. The results of this study can be used to design evidence-based control strategies, and to refine predictions of parasite epidemiology under changing climatic and management conditions. 


\section{Abbreviations}

GIN: Gastrointestinal nematode; ITS: Internal transcribed spacer; L3: Infective third-stage larvae; PCR: Polymerase chain reaction; rDNA: Ribosomal DNA.

\section{Supplementary Information}

The online version contains supplementary material available at https://doi. org/10.1186/s13071-021-05101-w.

Additional file 1: Table S1. Grass sampling dates for each pasture during the whole study period.

Additional file 2: Text S1. Validation of grass $L 3$ recovery and fecal $L 3$ recovery protocols. Recovery rates were calculated by spiking parasite-free grass and fecal samples with around $1000 \mathrm{L3s}$.

Additional file 3: Table S2. The proportion of L3 migrating out of fecal pats over the course of the entire grazing period was estimated by $X /$ $(X+Y)$, where $X$ is the sum of the mean number of $L 3$ on grass per pat at each sampling point over the grazing season and $Y$ is the mean number of $L 3$ remaining in each fecal pat at the end of the grazing season.

\section{Acknowledgements}

We are grateful to the University of Calgary, Agriculture and Agri-Food Canada, and all the farmers involved in the study, without whom it would never have been accomplished. We would also like to acknowledge the tremendous help provided by Dawn Gray during the fieldwork and laboratory work.

\section{Authors' contributions}

TW, DDC, ERM and JSG designed and developed the study. TW, SK and NM collected and processed the field samples. TW and SK analyzed the data. TW, EMR and AM carried out the ITS2 rDNA metabarcoding. TW and RC conducted the bioinformatics analysis. TW, JSG, ERM, CM and HRV wrote the manuscript. All authors read and approved the final manuscript.

\section{Funding}

This study was funded by the Beef Cattle Research Council (project ANH.04.17). CM and EM gratefully acknowledge funding from UK Research and Innovation through grant BB/R010250/1 and a Biotechnology and Biological Sciences Research Council-Canada partnering award (BB/T0200059/1).

\section{Availability of data and materials}

Data supporting the conclusions of this article are included in this published article and its additional files. All the raw sequences were submitted to the NCBI database (https://www.ncbi.nlm.nih.gov/sra/PRJNA783888) with accession number PRJNA783888.

\section{Declarations}

\section{Consent for publication}

Not applicable.

\section{Competing interests}

The authors declare that they have no competing interests.

\section{Author details}

${ }^{1}$ Host-Parasite Interactions Program, Faculty of Veterinary Medicine, University of Calgary, Calgary, Canada. ${ }^{2}$ School of Biological Sciences, Queen's University Belfast, Belfast, UK. Institute of Infection, Veterinary and Ecological Sciences, University of Liverpool, Liverpool, UK. ${ }^{4}$ Agriculture and Agri-Food Canada, Lethbridge, Canada.

Received: 15 September 2021 Accepted: 17 November 2021 Published online: 11 December 2021

\section{References}

1. Anderson N, Armour J, Jarrett WF, Jennings FW, Ritchie JS, Urquhart GM. A field study of parasitic gastritis in cattle. Vet Rec. 1965;77:1196-204.

2. Smith HJ, Perreault JP. A type 2 ostertagiasis outbreak in cattle in New Brunswick. Can Vet J. 1972:13:114-7.

3. Forbes AB, Cutler KL, Rice BJ. Sub-clinical parasitism in spring-born, beef suckler calves: epidemiology and impact on growth performance during the first grazing season. Vet Parasitol. 2002;104:339-44.

4. Hildreth MB, McKenzie JB. Epidemiology and control of gastrointestinal nematodes of cattle in northern climates. Vet Clin Food Anim. 2020:36:59-71.

5. Skuce PJ, Morgan ER, Van Dijk J, Mitchell M. Animal health aspects of adaptation to climate change: beating the heat and parasites in a warming Europe. Animal. 2013;7:333-45.

6. Morgan ER, Wall R. Climate change and parasitic disease: farmer mitigation? Trends Parasitol. 2009;25:308-13.

7. Gasbarre LC. Anthelmintic resistance in cattle nematodes in the US. Vet Parasitol. 2014;204:3-11.

8. Avramenko RW, Redman EM, Lewis R, Bichuette MA, Palmeira BM, Yazwinski TA, Gilleard JS. The use of nemabiome metabarcoding to explore gastro-intestinal nematode species diversity and anthelmintic treatment effectiveness in beef calves. Int J Parasitol. 2017;47:893-902.

9. Gibbs HC. The epidemiology of bovine ostertagiasis in the north temperate regions of North America. Vet Parasitol. 1988;27:39-47.

10. Stromberg BE, Corwin RM. Epizootiology of Ostertagia ostertagi in cow-calf production systems in the American Midwest. Vet Parasitol. 1993:46:297-302.

11. Nogareda C, Mezo M, Uriarte J, Lloveras J, Cordero del Campillo M. Dynamics of infestation of cattle and pasture by gastrointestinal nematodes in an Atlantic temperate environment. J Vet Med. 2006;53:439-44.

12. Larsson A, Dimander SO, Rydzik A, Uggla A, Waller PJ, Höglund J. A 3-year field evaluation of pasture rotation and supplementary feeding to control parasite infection in first-season grazing cattle-dynamics of pasture infectivity. Vet Parasitol. 2007;145:129-37.

13. Wang T, Avramenko RW, Redman EM, Wit J, Gilleard JS, Colwell DD. High levels of third-stage larvae (L3) overwinter survival for multiple cattle gastrointestinal nematode species on western Canadian pastures as revealed by ITS2 rDNA metabarcoding. Parasit Vectors. 2020;13:1-11.

14. Armour J, Duncan M. Arrested larval development in cattle nematodes. Parasitol Today. 1987:3:171-6.

15. Control of worms sustainably (COWS). 2020. https://www.cattleparasites. org.uk/. Accessed 24 Nov 2021.

16. Climate in Alberta. 2012. https://albertawater.com/virtualwaterflows/ climate-in-alberta. Accessed 20 Oct 2021.

17. Beck MA, Colwell DD, Goater CP, Kienzle SW. Where's the risk? Landscape epidemiology of gastrointestinal parasitism in Alberta beef cattle. Parasit Vectors. 2015;8:1-13.

18. Jelinski M, Gilleard J, Rocheleau L, Royan G, Waldner C. Epidemiology of gastrointestinal nematode infections in grazing yearling beef cattle in Saskatchewan. Can Vet J. 2017;58:1044-50.

19. Statistics Canada. 2020. https://www.statcan.gc.ca/en/subjects-start/agric ulture_and_food. Accessed 25 Oct 2021.

20. Yazwinski TA, Tucker CA. A sampling of factors relative to the epidemiology of gastrointestinal nematode parasites of cattle in the United States. Vet Clin Food Anim. 2006;22:501-27.

21. Avramenko RW, Redman EM, Lewis R, Yazwinski TA, Wasmuth JD, Gilleard JS. Exploring the gastrointestinal "nemabiome": deep amplicon sequencing to quantify the species composition of parasitic nematode communities. PLoS ONE. 2015;10:1-18.

22. Kim E-S, Sonstegard TS, Da Silva MVGB, Gasbarre LC, Van Tassell CP. Genome-wide scan of gastrointestinal nematode resistance in closed Angus population selected for minimized influence of MHC. PLOS ONE. 2015;10:1-18

23. Avramenko RW, Redman EM, Windeyer C, Gilleard JS. Assessing anthelmintic resistance risk in the post-genomic era: a proof-of-concept study assessing the potential for widespread benzimidazole-resistant gastrointestinal nematodes in North American cattle and bison. Parasitol. 2020;147:897-906.

24. Stromberg BE, et al. Prevalence of internal parasites in beef cows in the United States: results of the National Animal Health Monitoring System's (NAHMS) beef study, 2007-2008. Can J Vet Res. 2015;79:290-5. 
25. Yang C, Gibbs HC, Xiao L, Wallace CR. Prevention of pathophysiologic and immunomodulatory effects of gastrointestinal nematodiasis in calves by use of strategic anthelmintic treatments. Am J Vet Res. 1993;54:2048-55.

26. Hilderson H, Vercruysse J, Claerebout E, De Graaf DE, Fransen J, Berghen P. Interactions between Ostertagia ostertgi and Cooperia oncophora in calves. Vet Parasitol. 1995;56:107-19.

27. Wang T, et al. Microclimate has a greater influence than macroclimate on the availability of infective Haemonchus contortus larvae on herbage in a warmed temperate environment. Agric Ecosyst Environ. 2018;265:31-6.

28. Stromberg BE. Environmental factors influencing transmission. Vet Parasitol. 1997;72:247-56.

29. Gruner L. Strongyle larvae recovery from ovine faeces sampled on pasture: efficiency of the Baermannization and epidemiological interest of the technique. Amsterdam: IV International Symposium of Veterinary Laboratory; 1986. p. 186-9.

30. Van Wyk J, Mayhew E. Morphological identification of parasitic nematode infective larvae of small ruminants and cattle: a practical lab guide. Onderstepoort J Vet Res. 2013;80:1-14.

31. Callahan BJ, McMurdie PJ, Rosen MJJ, Han AW, Johnson A, Holmes SP. DADA2: High-resolution sample inference from Illumina amplicon data. Nat Methods. 2016;13:581-3.

32. Workentine $\mathrm{ML}$, et al. A database for ITS2 sequences from nematodes. BMC Genet. 2020. https://doi.org/10.1186/s12863-020-00880-0.

33. Murali A, Bhargava A, Wright ES. IDTAXA: a novel approach for accurate taxonomic classification of microbiome sequences. Microbiome. 2018. https://doi.org/10.1186/s40168-018-0521-5.

34. Burnham KP, Anderson DR. Model selection and multimodel inference: a practical information-theoretic approach. 2nd ed. New York: SpringerVerlag; 2002

35. Shaw DJ, Dobson AP. Patterns of macroparasite abundance and aggregation in wildlife populations: a quantitative review. Parasitology. 1995;111:S111-3.

36. Flota-Banuelos C, Martinez I, Lopez-Collado J, Mendoza MV, Hernandez $H G$, Fajersson P. Spatio-temporal pattern of larvae and eggs of gastrointestinal nematodes in cattle pastures in Veracruz, Mexico. Rev Biol Trop. 2013:61:1747-58.

37. Rossanigo CE, Gruner L. Moisture and temperature requirements in faeces for the development of free-living stages of gastrointestinal nematodes of sheep, cattle and deer. J Helminthol. 1995;69:357-62.

38. Chylinski C, Lherminé $\mathrm{E}$, Coquile M, Cabaret J. Desiccation tolerance of gastrointestinal nematode third-stage larvae: exploring the effects on survival and fitness. Parasitol Res. 2014:113:2789-96.

39. Callinan A, Westcott JM. Vertical distribution of trichostrongylid larvae on herbage and in soil. Int J Parasitol. 1986;16:241-4.

40. Khadijah S, Kahn LP, Walkden-Brown SW, Bailey JN, Bowers SF. Effect of simulated rainfall timing on faecal moisture and development of Haemonchus contortus and Trichostrongylus colubriformis eggs to infective larvae. Vet Parasitol. 2013;192:199-210.

41. Van Dijk J, Morgan ER. The influence of water on the migration of infective trichostrongyloid larvae onto grass. Parasitology. 2011;138:780-8.

42. Khadijah S, Kahn LP, Walkden-Brown SW, Bailey JN, Bowers SF. Translation of $\mathrm{H}$. contortus and T. colubriformis from egg to establishment in grazing sheep is unaffected by rainfall timing, rainfall amount and herbage height under conditions of high soil moisture in the Northern Tablelands of NSW. Vet Parasitol. 2013;197:204-11.

43. Tessier P, Dorchies P. Epidemiology of cattle strongylosis in France: results of herbal sampling in eight different areas. Rev Med Vet. 1997;148:237-40.

44. Suarez VH, Lorenzo RL. Ecology of the free-living stages of cattle nematodes during summer contamination in Argentina Western Pampas. Parasite. 2000;7:255-61.

45. Eysker M, Van Der Aar WM, Boersema JH, Githiori JB, Kooyman FN. The effect of repeated moves to clean pasture on the build up of gastrointestinal nematode infections in calves. Vet Parasitol. 1998;76:81-94.

46. Rose H, Wang T, Van Dijk J, Morgan ER. GLOWORM-FL: a simulation model of the effects of climate and climate change on the free-living stages of gastro-intestinal nematode parasites of ruminants. Ecol Modell. 2015;297:232-45

47. Waghorn TS, et al. Dynamics of the free-living stages of sheep intestinal parasites on pasture in the North Island of New Zealand. 1. Patterns of seasonal development. NZ Vet J. 2011;59:279-86.
48. Claerebout E, Vercruysse J, Dorny P, Demeulenaere D, Dereu A. The effect of different infection levels on acquired resistance to gastrointestinal nematodes in artificially infected cattle. Vet Parasitol. 1998;75:153-67.

49. Grenfell BT, Smith G, Anderson RM. Maximum-likelihood estimates of the mortality and migration rates of the infective larvae of Ostertagia ostertagi and Cooperia oncophora. Parasitology. 1986;92:643-52.

50. Ravinet N, Bareille N, Lehebel A, Ponneau A, Chartier C, Chauvin A. Change in milk production after treatment against gastrointestinal nematodes according to grazing history, parasitological and production-based indicators in adult dairy cows. Vet Parasitol. 2014;201:95-109.

51. Verschave SH, Vercruysse J, Claerebout E, Rose H, Morgan ER, Charlier J. The parasitic phase of Ostertagia ostertagi: quantifiction of the main life history traits through systematic review and meta-analysis. Int J Parasitol. 2014:44:1091-104.

52. Charlier J, et al. Practices to optimise gastrointestinal nematode control on sheep, goat and cattle farms in Europe using targeted (selective) treatments. Vet Rec. 2014;175:250-5.

53. Hodgkinson J, et al. Refugia and anthelmintic resistance: concepts and challenges. Int J Parasitol Drugs Drug Resist. 2019;10:51-7.

\section{Publisher's Note}

Springer Nature remains neutral with regard to jurisdictional claims in published maps and institutional affiliations.
Ready to submit your research? Choose BMC and benefit from:

- fast, convenient online submission

- thorough peer review by experienced researchers in your field

- rapid publication on acceptance

- support for research data, including large and complex data types

- gold Open Access which fosters wider collaboration and increased citations

- maximum visibility for your research: over $100 \mathrm{M}$ website views per year

At BMC, research is always in progress.

Learn more biomedcentral.com/submissions 